

\section{FACTORES QUE INTERVIENEN EN LA MEDIACIÓN PEDAGÓGICA DISCIPLINAR DURANTE EL ESTUDIO A DISTANCIA EN LA UNIVERSIDAD JUÁREZ AUTÓNOMA DE TABASCO}

FACTORS INVOLVED IN DISCIPLINARY PEDAGOGICAL MEDIATION DURING DISTANCE STUDY IN THE UNIVERSIDAD JUÁREZ AUTÓNOMA DE TABASCO

\section{GUADALUPE EMMANUEL JIMÉNEZ MARGALLI RIGOBERTO GARCÍA CUPIL}

\section{RESUMEN}

La educación a distancia se ha constituido en una modalidad de importantes contribuciones y posibilidades, en su mayoría las Instituciones de Educación Superior (IES) han diversificado su oferta y han accedido a los sistemas no convencionales como lo representa esta modalidad. Tal ha sido el caso de la Universidad Juárez Autónoma de Tabasco (UJAT) quien a través del Sistema de Educación a Distancia (SEaD) ha propiciado un sistema de apoyo presencial con oferta a distancia de asignaturas y programas educativos en su totalidad. Los procesos formativos en este esquema en el SEaD UJAT son mediados por el uso de una plataforma tecnológica de código abierto a través de Moodle. Sin embargo, las adecuaciones tecnológicas y el apoyo de diversos agentes no subsanan las deficiencias de la mediación pedagógica y disciplinar carente por parte del profesorado que participa en este sistema. Ante esto, este trabajo esboza los principales factores que intervienen en estas limitantes.

PALABRAS CLAVE: Descriptores - Distancia - Interactividad - Variables - Tic - Educación.
ABSTRACT

Distance education has become a modality of important contributions and possibilities, mostly Higher Education Institutions have diversified their offer and have accessed unconventional systems as represented by this modality. Such has been the case of the Universidad Juárez Autónoma de Tabasco (UJAT) which, through the Distance Education System, has fostered a face-to-face support system with a distance offering of all educational subjects and programs. The training processes in this scheme are mediated by the use of an open source technological platform through Moodle. However, the technological adaptations and the support of various agents do not correct the deficiencies of the pedagogical and disciplinary mediation lacking on the part of the teachers who participate in this system. Given this, this work outlines the main factors that interfere in these limitations.

KEYWORDS: Descriptors - Distance - Interactivity - Variables - Tic - Education. 
L os procesos formativos de una modalidad a distancias requieren de más elementos que en la educación convencional pueden ser omitidos, el trabajo de agentes y profesores debe ser redoblado y la posición autogestiva de quien aprende debe caracterizar la formación y el aprendizaje. Ante esto, y en apego a las políticas de inclusión, cobertura, equidad y democratización de la educación pública en el país, desde el 2007 la UJAT a través del SEaD ofrece asignaturas en modalidad a distancia que forman parte de los programas presenciales de la institución, procurando con esto, además de lo expuesto, esquemas de flexibilidad a los estudiantes.

La oferta es posible por el uso de una plataforma tecnológica, misma que evidencia las limitaciones formativas para el alumno universitario, cuando éste se convierte en usuario de este sistema de educación. Dentro de lo que destaca es la escasa comunicación entre el alumno y el docente, trayendo así repercusiones para el usuario.

Al inicio del ciclo escolar para cursar asignatura en la modalidad el alumno no está familiarizado con el uso de la plataforma y desconoce la manera adecuada de interactuar en ésta, se distingue a su vez, que los procesos de retroalimentación por parte del docente son muy tardados, incluso excedente al tiempo establecido para abrir los foros de conversación y comunicación con el alumno, creando inquietud y llevándolo a preocuparse más por la situación. Situación que propicia la baja de asignatura y rezago en su flujo ideal de la carrera, también viéndose afectado cuando el maestro carga todas las tareas atrasadas para un determinado tiempo así el alumno no tiene un aprendizaje factible dejando fuera también la comunicación que debería existir entre los dos personajes principales.

El propósito principal de este trabajo pretende identificar los factores que inciden para que el alumno no tenga una comunicación eficaz con el docente y también cuáles barreras son las que surgen en este proceso que afectan el aprendizaje en esta plataforma educativa.

La investigación se sustenta en la teoría de la interacción de Nathan Shedroff, que se basa en 6 niveles de interactividad: Comunicación, Control, Feedback, Productividad, Creatividad y Adaptabilidad. Es viable sustentar la investigación con esta teoría ya que abarca en sus 6 niveles los procesos que deben existir entre el alumno y docente sin dejar fuera la plataforma de educación a distancia.

Las condiciones para realizarlo son factibles considerando que de la experiencia de los alumnos y de la observación, se hace valer algunos rasgos que implican y permitirán un diagnóstico de este grupo social que son los alumnos de la UJAT. El trabajo a realizar requiere más de tiempo que de una aportación económica 0 de algún traslado fuera de las posibilidades, teniendo en cuenta que hay accesibilidad a este sistema siendo alumno de la universidad.

Las aportaciones que puede arrojar serían de beneficio para la comunidad universitaria, desde una perspectiva holística ya que se podría ver inmersa en una propuesta para la institución para mejorar el servicio de educación a distancia a través de su plataforma y principalmente mejoraría el nivel de aprendizaje de sus alumnos usuarios.

\section{DESARROLLO}

La comunicación se puede definir como un proceso por medio del cual una persona se pone en contacto con otra a través de un mensaje, y espera que esta última de una respuesta, sea una opinión, actividad o conducta. En otras palabras, la comunicación es una manera de establecer contacto con los demás por medio de ideas, hechos, pensamientos y conductas, buscando una reacción al comunicado que se ha enviado. Generalmente, la intención de quien comunica es cambiar o refor-

\section{La teoría de la interacción de Nathan Shedroff} se basa en 6 niveles de interactividad: comunicación, control, feedback, productividad, creatividad y adaptabilidad, procesos que deben existir entre el alumno-docente sin dejar fuera la plataforma de educación a distancia 
zar el comportamiento de aquel que recibe la comunicación (Martínez de Velasco y Nonski, 2002).

Con la globalización han surgido varias necesidades educativas que demandan estrategias de enseñanza-aprendizaje innovadora y motivadora, para las cuales los alumnos deben tener mejor aprovechamiento del tiempo. A la par han nacido las TIC, que representan un fuerte apoyo a la educación a distancia y se basan en un modelo pedagógico-tecnológico. En esta modalidad educativa el alumno es lo más importante en el proceso de enseñanza-aprendizaje.

Refiere Rosario González en el artículo Las TICs como estrategia de comunicación educativa en el mundo globalizado, lo siguiente:

La comunicación tecnológica se ha vuelto una herramienta necesaria en el mundo de hoy. Ésta abre al individuo otras posibilidades a distintos campos de análisis, a otras concepciones de la realidad de sí mismo, a una concepción del cosmos, en donde las oportunidades son infinitas e implican la integración de la tecnología y lo educativo, con conceptos dinámicos, pedagógicos y de actualidad.

Bajo este contexto, es importante que todos los docentes estén conscientes de proporcionar al alumno una educación integral, en la que se debe abarcar lo social, cognoscitivo, cultural y espiritual.

La educación a distancia permite al alumno mediante una comunicación formal expresar sus opiniones respecto a algún documento, lectura 0 material de aprendizaje; además de que es muy cómodo acceder a la información, es más rápido y viable; por consecuencia es motivante para el alumno. Para el profesor también es cómodo, ya que rápidamente envía el material y establece comunicación de manera más eficiente con los alumnos a cualquier hora del día y cualquier día de la semana.

Todos los sistemas educativos deben prestar atención a los cambios que están surgiendo en el campo tecnológico, ya que no podemos negar la influencia tan fuerte que están teniendo las telecomunicaciones en las personas; así pues, el cuerpo docente debe

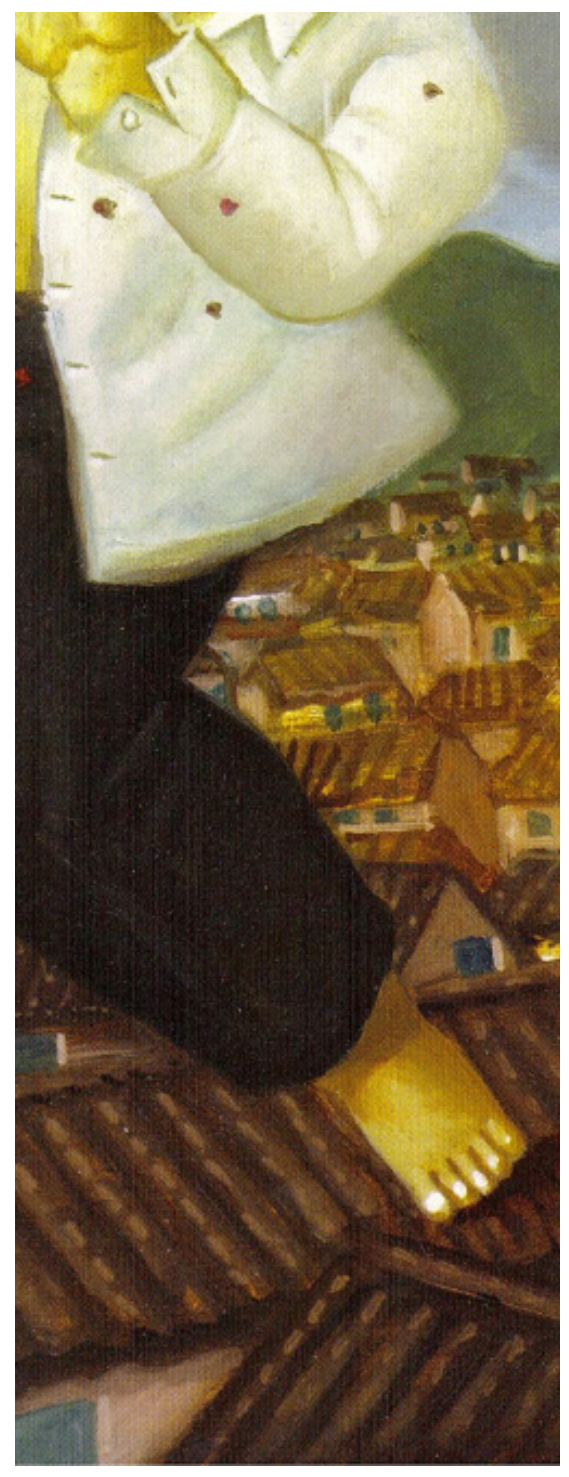

estar actualizado y con disposición de mejorar y adaptarse a esta nueva realidad.

\section{EL DISEÑO DE LA EDUCACIÓN A DISTANCIA}

Al diseñar la Educación a Distancia mediante las tecnologías de información se debe tomar en cuenta principalmente el objetivo que queremos lograr, qué tipo de egresados pretendemos formar y cuáles serán los diseños tecnológicos que para ello necesitamos.

Es bien sabido que en la actualidad se requiere que la enseñanza esté centrada en el alumno, pues lo importante no es sólo lo que el profesor enseña, sino lo que el alumno aprende, cómo lo aprende y para qué lo aprende.

Se debe tener cuidado al realizar un diseño instruccional para educación a distancia, ya que esta modalidad conlleva flexibilidad para el alumno en su aprendizaje; por lo tanto se puede desviar del objetivo principal. Sin embargo, una ventaja de esta flexibilidad en el factor tiempo; por ejemplo, puede significar para el alumno una fuente importante de motivación, ya que él puede distribuirlo como lo considere conveniente.

En la educación a distancia es necesario que el docente tenga conocimientos en el área de la comunicación para que ésta sea más eficiente y los mensajes fluyan bidireccionalmente. La educación a distancia, paradójicamente, debe tener extrema cercanía entre todos los participantes.

Es importante señalar que en la modalidad de educación a distancia se puede tener como apoyo el método 
de aprendizaje basado en problemas $(\mathrm{PBL})$, que permite el intercambio de opiniones, el razonamiento crítico y propuestas de soluciones, utilizando como apoyo didáctico el análisis de diferentes casos-problema surgidos en el ámbito en el cual se está formando el alumno (Del toro, S.F.).

\section{LA INTERACTIVIDAD DE NATHAN SHEDROFF}

La interactividad implica relacionarse a través de medios técnicos y compartir todo tipo de información entre usuarios. Según la teoría de Nathan Shedroff, existen cinco niveles de interactividad:

1. CONTROL: Es la capacidad del usuario para regular el sistema. Algunas páginas web, como la de Bijou Brigitte, permiten traducir el contenido a diferentes idiomas y acceder a diferentes secciones por medio de links. Otras también regulan el tamaño del texto.

2. FEEDBACK: Información sobre el resultado de las acciones del usuario. Un ejemplo son los avisos que aparecen en Microsoft Word cuando queremos cerrar un documento sin haberlo guardado. El ordenador nos pregunta si realmente queremos continuar y nos recuerda que, en ese caso, perderemos la información. La barra de descarga, el informe de un error, son otros ejemplos de feedback.

3. PRODUCTIVIDAD: Es la capacidad de elaborar cosas útiles, es decir, aplicaciones de productividad. Un claro ejemplo en este campo es el Google Calendar, que permite al usuario planificar su día a día a través de un calendario, notas, avisos. En esta sección también se incluyen los traductores, conversores, el Google Docs.
4. CREATIVIDAD: Capacidad de elaborar cosas bellas, originales, artísticas y divertidas. Aquí entra cualquier aplicación de entretenimiento como, por ejemplo, todos los gadgets que podemos incorporar al iGoogle.

5. ADAPTABILIDAD: Capacidad de ajuste del sistema en función del comportamiento del usuario. Se trata de una ayuda sensible al contexto y se basa en el reconocimiento y la personalización del usuario. Cabe destacar el Clippo, la ayuda que ofrece Microsoft Word para solucionar dudas y problemas.

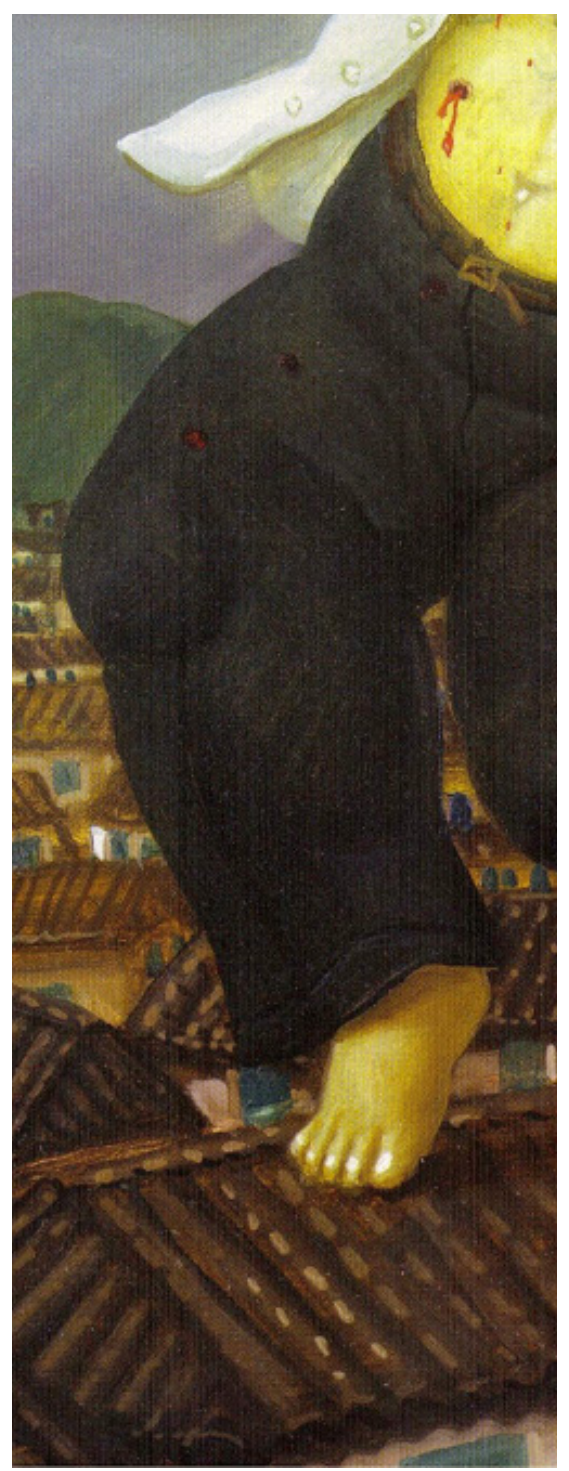

6. COMUNICACIÓN: Capacidad del sistema para facilitar el diálogo entre usuarios (foros, chats, blogs, microblogs, apps de mensajería instantáneas). Aunque hay miles de ejemplos en este ámbito, una de las redes sociales más empleadas en España actualmente es el Tuenti, al igual podemos citar, además, Facebook, Twitter, blogs como el de Comunicación Digital y toda clase de foros.

La interactividad es entendida como la capacidad de los participantes en el proceso para intercambiar roles en la emisión de sus discursos, esto es, la interactividad se encuentra reducida a los servicios de comunicación sincrónica que la Red ofrece.

Por su parte Kramer (s.f.), sostiene que esta interactividad telemática presenta rasgos distintivos que deben ser considerados en la conceptualización del proceso comunicativo, como es que en Internet es posible interactuar con datos y no directamente con personas, es decir, se establecería una primera relación material más que personal. En este proceso se prescinde del aspecto ilocutivo o paralingüístico de la actividad simbólica, la interacción tiene el estatus de juego, el universo de datos legibles en la máquina es la exteriorización del principio de la intertextualidad, y se crea una nueva forma de memoria colectiva.

\section{BARRERAS IMPLICADAS \\ EN ESTE SISTEMA EDUCATIVO}

Dentro de la comunicación es necesaria y esencial para el ser humano, y aunque es parte cotidiana de nuestras vidas, la realidad es que nos cuesta mucho trabajo comunicarnos bien; no importa los adelantos tecnológicos en 


\section{Aun cuando el Emisor y el Receptor pongan}

\section{todo de su parte para lograr comunicarse}

eficientemente, existen interferencias que pueden

rebasar el control que se pretenda, limitando

la comprensión del mensaje

materia de comunicación, el hombre

moderno está cada vez más aislado y

tiene mayores problemas para entrar

en verdadero contacto con sus seme-

jantes; muchas veces porque antepo-

nemos obstáculos que entorpecen la comunicación.

Aun cuando el Emisor y el Receptor pongan todo de su parte para lograr comunicarse eficientemente, existen interferencias que pueden rebasar el control que se pretenda, limitando la comprensión del mensaje. Parte de nuestra condición humana o de las circunstancias ambientales externas que salen de nuestro control, van a impedir una comunicación eficaz y eficiente. Estas causas de interferencia en el proceso de comunicación se denominan Barreras (Quijada y Torres, s.f).

Los alumnos reconocen que su relación con la tecnología ha cambiado cuando han sido capaces de manejar los códigos que les permiten no sólo crear sus propios textos (páginas web, presentaciones, software educativo), sino interactuar en línea con otros usuarios, incluidos sus profesores. Si el análisis se remite a la variable tecnológica, como usuarios establecemos un vínculo directo con las redes de computación y, en general, con los sistemas de comunicación digital.

\section{MODELO DE EDUCACIÓN A DISTANCIA UJAT (SEaD)}

La Universidad Juárez Autónoma de Tabasco, planteó por primera vez en el Plan de Desarrollo Institucional 19881992, la necesidad de integrar nuevas modalidades educativas que satisfagan las demandas de la sociedad en virtud de los retos de la globalización y del cambio tecnológico a los que se comenzaron a enfrentar las IES. La historia de la educación abierta y a distancia en esta Casa de Estudios, se ha gestado y desarrollado a lo largo de dos décadas, en un principio mediante cursos y diplomados transmitidos por televisión y vía satélite para la formación docente y profesional, hasta programas de licenciatura y posgrado en los que se utilizan TIC's que permiten superar obstáculos de diversa índole.

El modelo de Educación Abierta y a Distancia en México se encuentra en constante construcción y reconstrucción, al menos en 2 niveles: Conceptual y Operativo, que incluye el diseño curricular y soportes tecnológicos.
De hecho, el panorama general de la educación a distancia en las IES está relacionado con una gran diversidad de modelos educativos:

Más de 50 instituciones utilizan esta modalidad con sus propios conceptos, matices y mezclas, de manera que no se puede hablar de un solo estilo, sino de una gran variedad de esquemas educativos, con todas las ventajas e inconvenientes que ello implica (Moreno, 2006, p115).

Lo anterior se sustenta en las líneas para el desarrollo de un modelo educativo propuestas por la ANUIES, las cuales están fundamentadas en el desarrollo de programas y acciones educativas de la modalidad, supone la necesidad de establecer un modelo institucional que satisfaga las condiciones básicas al menos en 2 niveles:

- Conceptual: que debe incluir la misión, visión y fines institucionales, así como la concepción de las relaciones sociales, el conocimiento, la enseñanza y el aprendizaje.

- Operativa: que incluye el diseño instruccional y el curricular, además del soporte tecnológico adecuado.

SEaD son las siglas que dan identidad al Sistema de Educación a Distancia de la Universidad Juárez Autónoma de Tabasco. La Dirección de Educación a Distancia es la instancia administrativa que integra y coordina el trabajo de los actores que intervienen en el sistema con la finalidad de gestionar, otorgar y asegurar la existencia de los recursos materiales, tecnológicos y humanos que contribuyan al logro de los objetivos institucionalmente establecidos para la modalidad. 
El Modelo Institucional del SEaD está basado en la concepción pedagógica constructivista y humanista del aprendizaje. Bajo esta perspectiva su estrategia educativa en la que se centra en el estudiante.

El SEaD ofrece una alternativa de formación en educación superior a las personas que trabajan y desean cursar o concluir una carrera profesional sin tener que separarse de su actividad laboral, por lo que la educación a distancia se define como una modalidad educativa caracterizada por la responsabilidad de enseñar, generar, aplicar conocimientos y construir aprendizaje haciendo uso de las tecnologías de la información y la comunicación para mediar el diálogo entre estudiantes y profesores separados en tiempo y espacio, potenciando un aprendizaje independiente y flexible.

- La Misión: Brindar educación a través del uso de un modelo pedagógico apoyado de tecnologías que permitan ampliar la cobertura con equidad para formar profesionales capaces de aplicar los conocimientos y valores adquiridos al entorno social, económico, científico y tecnológico, en el contexto internacional, nacional y el Estado de Tabasco.

- La Visión: Ser un sistema de Educación a Distancia que brinda programas educativos acreditados por los organismos correspondientes que propicien el intercambio académico y la movilidad estudiantil, y contribuir a la formación de profesionales e investigadores de alto nivel.

- El Objetivo: Ofrecer una alternativa de educación vanguardista e innovadora que apoye al sistema

EI SEaD ofrece una alternativa de formación en educación superior a las personas que trabajan y desean cursar o concluir una carrera profesional sin tener que separarse de su actividad laboral haciendo uso de las tecnologías de la información y la comunicación

escolarizado para ampliar la cobertura, brindar equidad y acceso a la Educación Superior.

\section{CARACTERÍSTICA SEAD-UJAT}

- El estudiante desarrolla su aprendizaje bajo la orientación del docente tutor.

- Combina estrategias, métodos y medios tecnológicos didácticos.

- El estudiante aprende con la orientación de guías didácticas posibilitando la autoevaluación.

- Tiene capacidad de aprender más allá de un aula, eliminando las barreras de tiempo y espacio por lo que no implica la asistencia a clases.

- Garantiza al estudiante la misma calidad de aprendizaje que en la modalidad escolarizada.

\section{METODOLOGÍA DE TRABAJO DEL SEaD - UJAT}

- Proporciona un ambiente flexible, dinámico y práctico que le permite al estudiante administrar su tiempo y ser el protagonista de su propio aprendizaje.

- El profesor guía y orienta el aprendizaje del estudiante, a través de estrategias de enseñanza y actividades para que éste adquiera las competencias señaladas en su Plan de Estudio.

- Se apoya del uso de la plataforma tecnológica institucional a través de las aulas virtuales en donde interactúan los profesores y alumnos.

- Se brinda asesorías en línea.

- Cuenta con una Guía Didáctica que tienen la función de informar al estudiante de lo que aprenderá en el curso y lo que tiene que hacer para lograrlo.

- En cada División Académica hay un Tutor de Seguimiento quien es el responsable de atender y resolver asuntos académicos y tecnológicos de profesores y alumnos que se presenten durante el desarrollo de las asignaturas. En caso de dudas el estudiante puede dirigirse al Tutor de Seguimiento, además del profesor.

\section{MEDIOS/HERRAMIENTAS}

Los medios asociados con las nuevas tecnologías son aquellos que tienen como fundamento la transmisión de datos de manera digital y están relacionados con el uso de internet y los equipos de cómputo con sus diferen- 
tes dispositivos, por lo que en esta modalidad son diversos los medios y recursos tecnológicos de comunicación que todos los implicados hacen uso durante el proceso de enseñanza aprendizaje, dentro de los que se encuentran:

\section{- Sistema de Gestión del Conoci-} miento (Plataforma Tecnológica SEaD-UJAT): es una aplicación informática que soporta tanto la distribución de materiales y contenidos como aplicaciones y recursos de comunicación sincrónicos y asincrónicos, proporcionando un espacio para el desarrollo de la actividad académica a distancia.

- Aula Virtual: entorno virtual de enseñanza aprendizaje en el que se desarrolla un curso. Se basa en herramientas de interacción e integrado por la guía didáctica, los materiales y recursos donde los estudiantes participan y tienen la posibilidad de comunicarse, aprender y desarrollar habilidades y competencias con la ayuda del profesor.

- Sitio Web: conjunto de páginas con soporte electrónico que pertenece a una organización (Universidades, Academias, Bibliotecas, Museos, Organismos públicos y privados, nacionales e internacionales) o a una persona. Cada sitio presenta un menú con diferentes opciones para acceder a múltiples recursos sobre temáticas específicas de interés para grupos determinados.

- Foro: es un escenario de comunicación por internet, donde se propicia el debate, la concertación y el consenso de ideas, lo que permite a un usuario publicar su mensaje en cualquier momento

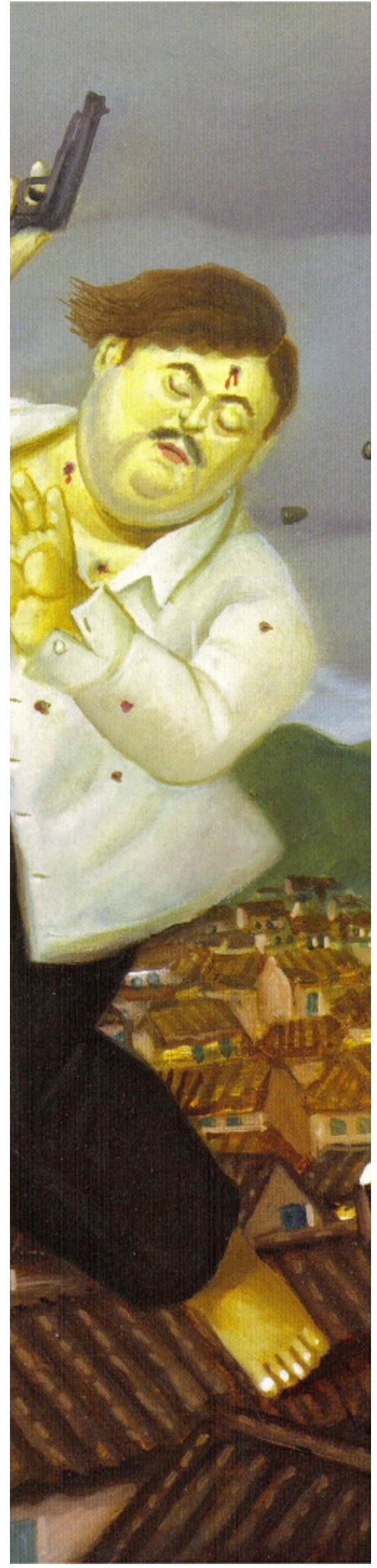

quedando visible para que otros sujetos que accedan en otro momento puedan visualizarlo.

- Correo Electrónico: servicio de internet que permite intercambiar mensajes en tiempo diferido (asincrónico) y enviar datos (textos, imágenes, sonido, animaciones) de persona a persona 0 de una persona a diversos receptores (llamadas listas de interés 0 de discusión). El propósito de esta herramienta tecnológica es que el estudiante tenga una alternativa más para contactar a su profesor.

- Teléfono: medio de comunicación síncrono que permite la resolución de dudas presentadas durante el proceso de enseñanza aprendizaje.

- Redes Sociales: formas de interacción social dadas en un entorno web. Se define por el intercambio dinámico entre personas, en este caso estudiantes, profesores y responsable de Departamento de Seguimiento y Evaluación, donde la principal función es el intercambio de experiencias, la difusión de información relacionada con los procesos, resolución de dudas y otros temas.

\section{MÉTODO}

El alcance de este proyecto es correlacional ya que se enfocara en las variables; el alumno, el profesor y la plataforma de educación a distancia, así como se podrá conocer el comportamiento actual de estos, se podría predecir un futuro basado en una propuesta de mejora para la institución educativa que brinda el uso de la plataforma UJAT, pero todo a raíz de la detección de las barreras que impiden una buena comunicación e interactividad entre el alumno y el profesor 
haciendo uso de la plataforma educativa, también si existe un tal grado de asociación entre estos mismos.

Implica ser correlacional porque se puede partir de una hipótesis y también llevar a comprobarlas como por ejemplo se puede decir que:

La falta de comunicación e interactividad en la plataforma es porque el alumno no tiene interés en la materia.

Esta hipótesis se podría llevar a su comprobación mediante la medición de la variable (alumno) y vincularse con una segunda variable (profesor) y partir de aquí para la comprobación.

Se basa en el diseño cualitativo de investigación acción, relacionando la investigación como un problema dentro de la sociedad estudiantil, el hecho de que la plataforma de educación a distancia de la UJAT preste este servicio educativo sea implementado erradamente, dentro de lo cual hay diversos factores que convierten en un problema cotidiano para el alumno usuario de este servicio, este tipo de diseño de investigación cualitativo ayudará en el sentido de que se puede proponer una mejora para este sistema de educación a distancia, relacionando a los usuarios con la idea de ser conscientes y mejorar la calidad del aprendizaje que se podría obtener con esta herramienta educativa.

La técnica idónea es la encuesta, ya que es más rápida y eficaz para obtener la información. En este sentido la encuesta se aplicaría a los alumnos que han llevado materias en el sistema de educación a distancia de la UJAT, para saber la experiencia de los que ya pasaron por ese filtro de modalidad edu-

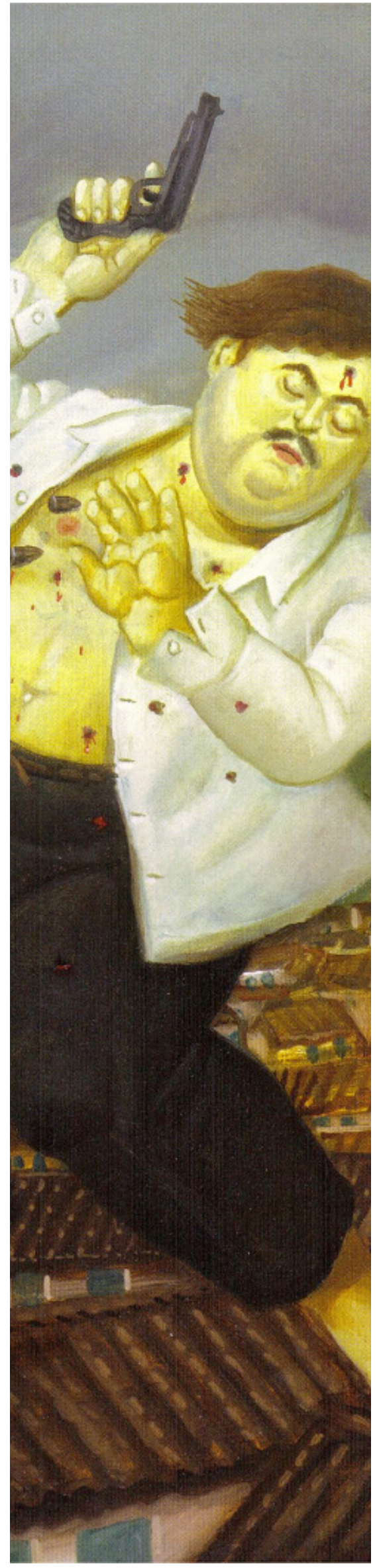

cativa y los que aún están mediados por dicha plataforma de educación para comparar si hay variación de las experiencias, usos de la plataforma y sobre todo del aprendizaje.

El instrumento a usar para la recolección de información es el cuestionario, en el cual lleva consigo 10 preguntas y para la extracción de resultados se tomaron las más importantes lo cual nos da una respuesta más amplia. Se estructuraron preguntas dadas a la problemática que se percibía por las experiencias de los compañeros estudiantes y que llevan, o están, planteadas dentro de nuestro planteamiento.

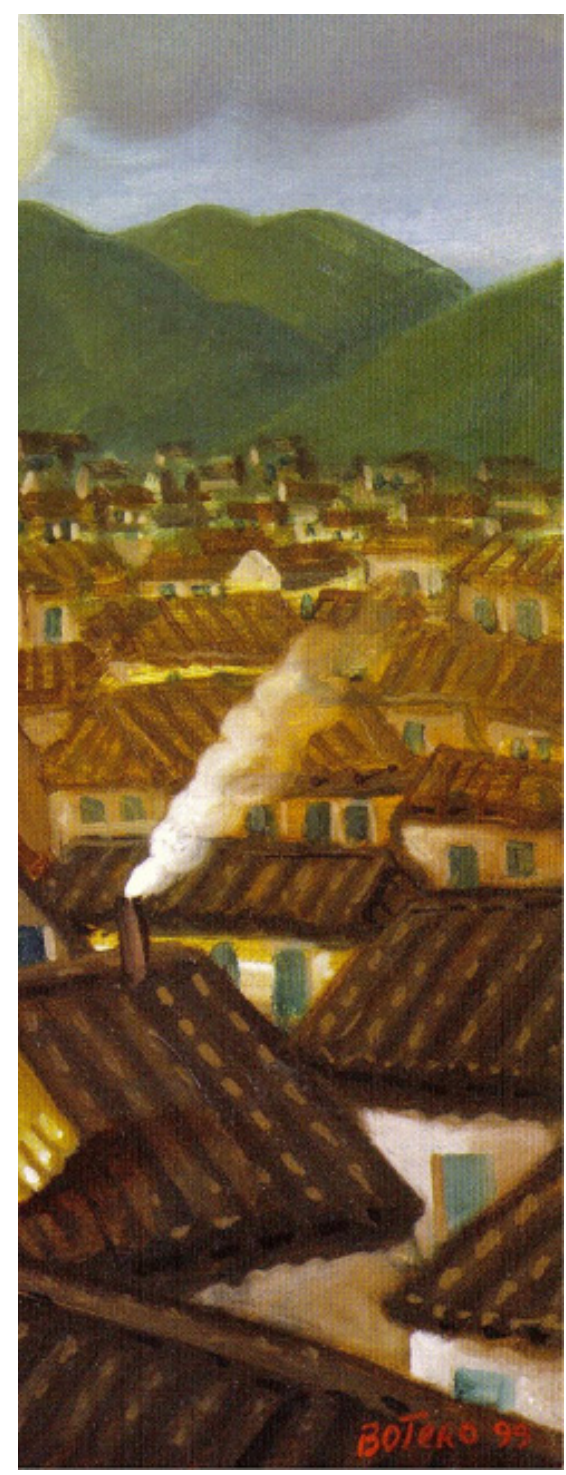




\section{RESULTADOS}

Elección de la Materia. Basados en el cuestionario que se aplicó los alumnos para elegir la modalidad de cursar una materia a distancia mostraron los siguientes resultados, que se analizaran de la gráfica anterior; el $36 \%$ de los alumnos que respondieron el cuestionario afirman que eligieron la modalidad a distancia para agilizar su flujo de materias y así poder terminar su trayectoria académica en tiempo y forma, aprovechando la opción que la universidad les ofrece ya que en cierta forma no tendrían que llegar a una clase presencial. El 6\% indicó que todo depende por el tiempo que se le invierte a las clases a distancia, ya que a diferencia de lo convencional se le puede dedicar tiempo en un lapso para checar y realizar tareas habiéndose de un plan no tan riguroso como el presencial. Por su parte el $28 \%$ respondió que es más práctico y fácil llevar las materias en línea siempre y cuando se las oferte la universidad, hay más practicidad para ellos. El 22 $\%$ indicó que no tuvo otra opción para cursar la materia al momento de elegir entre lo convencional y la modalidad a distancia.

ELECCION DE LA MATERIA

\begin{tabular}{|ll|r|r|r|r|}
\hline & & & & & $\begin{array}{c}\text { Porcentaje } \\
\text { acumulado }\end{array}$ \\
\hline Válidos & FLUJO DE MATERIA & Frecuencia & Porcentaje & Porcentaje válido & 39.1 \\
& TIEMPO INVERTIDO & 18 & 36.0 & 39.1 & 6.5 \\
& MAS PRACTICO & 3 & 6.0 & 35.7 \\
& NO TUVE OTRA OPCION & 14 & 28.0 & 76.1 \\
& Total & 11 & 22.0 & 23.9 & 100.0 \\
Perdidos & sin contestar & 46 & 92.0 & 100.0 & \\
Total & & 4 & 8.0 & 100.0 & \\
\hline
\end{tabular}

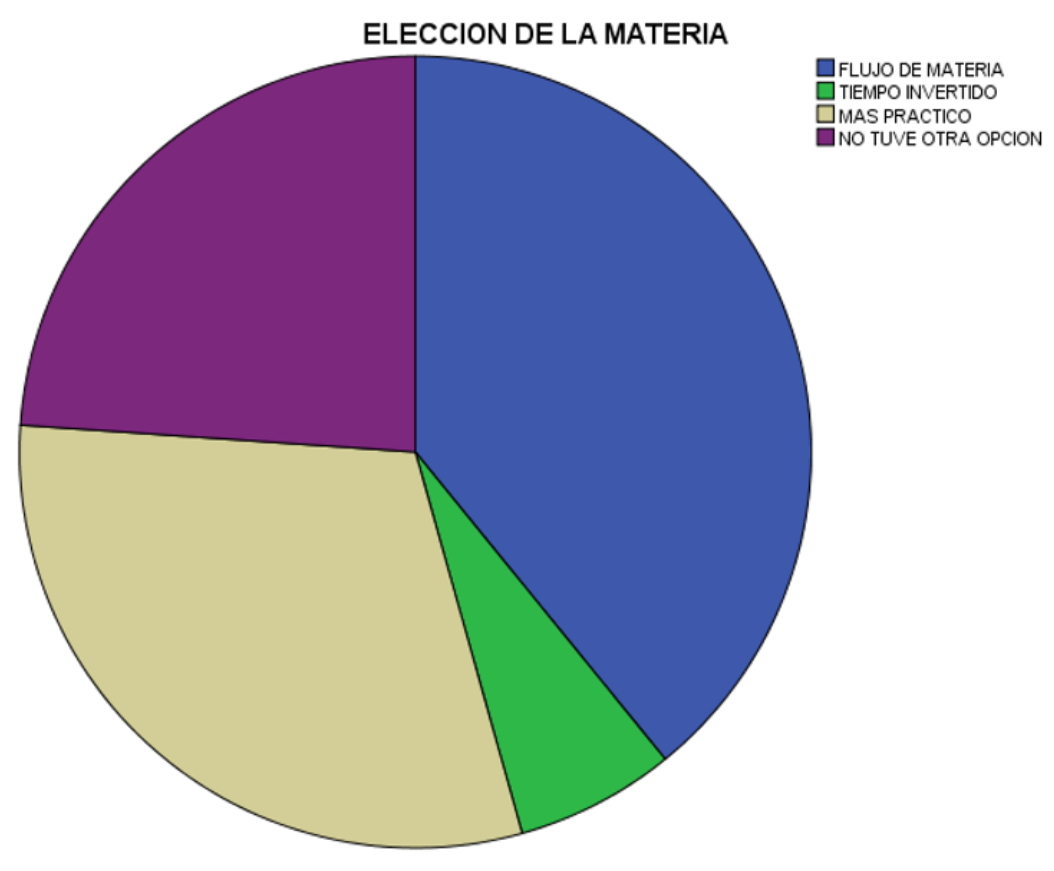


Cuantas veces cursados. Los alumnos arrojaron los siguientes datos; el $30 \%$ no ha cursado ni una sola vez una materia en la plataforma de la UJAT, el 60\% solo una vez ha cursado una materia en línea y solo el $10 \%$ ha cursado en dos ocasiones materias en línea.

CUANTAS VECES CURSADOS

\begin{tabular}{|ll|r|r|r|r|}
\hline & Frecuencia & Porcentaje & $\begin{array}{c}\text { Porcentaje } \\
\text { válido }\end{array}$ & $\begin{array}{c}\text { Porcentaje } \\
\text { acumulado }\end{array}$ \\
\hline Válidos & NUNGUNA & 15 & 30.0 & 30.0 & 30.0 \\
& 30 & 60.0 & 60.0 & 90.0 \\
UNA & 5 & 10.0 & 10.0 & 100.0 \\
Total DE DOS & 50 & 100.0 & 100.0 & \\
\hline
\end{tabular}

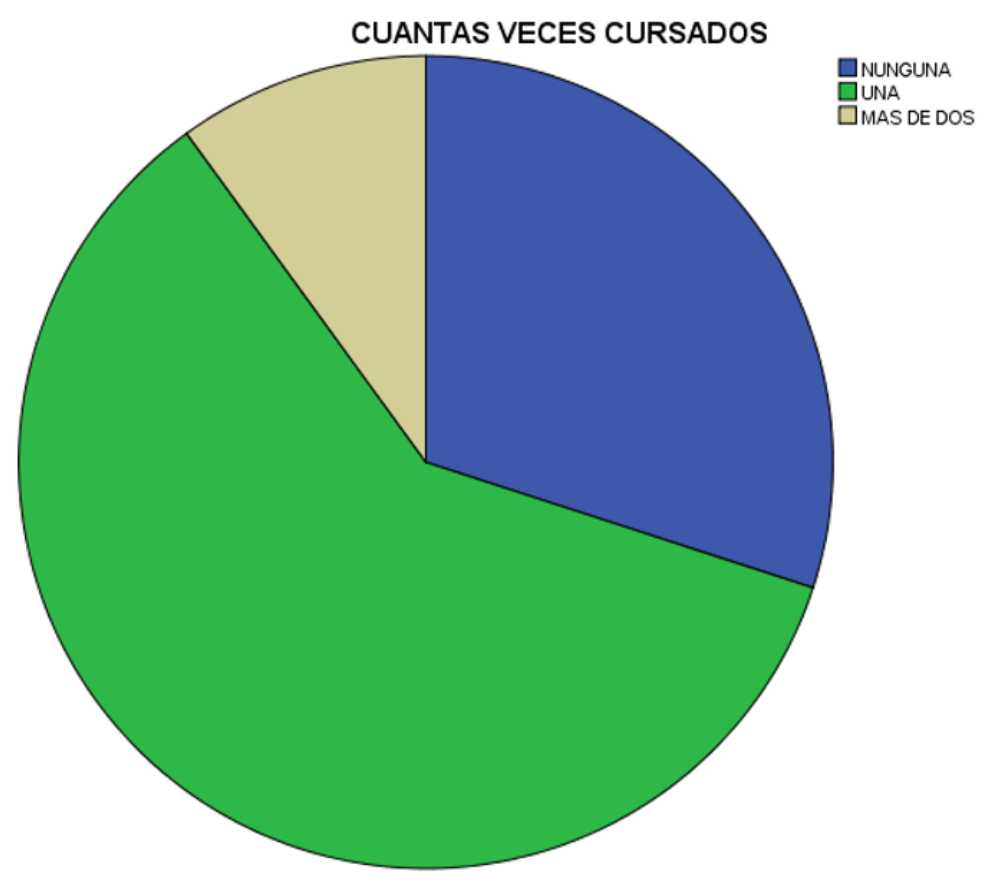


Cómo te enteraste. La forma en la que los alumnos se enteraron de la modalidad a distancia que ofrece la universidad fue; $38 \%$ por la publicidad institucional que emite en sus diversos formatos la UJAT, el 20\% por recomendaciones de sus profesores o tutores académicos y el $42 \%$ por recomendaciones de alumnos compañeros que por experiencia ya habían hecho uso de la plataforma.

COMO TE ENTERASTE

\begin{tabular}{|ll|r|r|r|r|}
\hline & Frecuencia & Porcentaje & \multicolumn{1}{c|}{$\begin{array}{c}\text { Porcentaje } \\
\text { válido }\end{array}$} & $\begin{array}{r}\text { Porcentaje } \\
\text { acumulado }\end{array}$ \\
\hline Válidos & $\begin{array}{l}\text { PUBLICIDAD } \\
\text { INSTITUCIONAL } \\
\begin{array}{l}\text { RECOMENDACION } \\
\text { PROFESORES }\end{array}\end{array}$ & 19 & 38.0 & 38.0 & 38.0 \\
$\begin{array}{l}\text { RECOMENDACION } \\
\text { ALUMNOS }\end{array}$ & 21 & 42.0 & 20.0 & 58.0 \\
Total & 50 & 100.0 & 42.0 & 100.0 \\
\hline
\end{tabular}

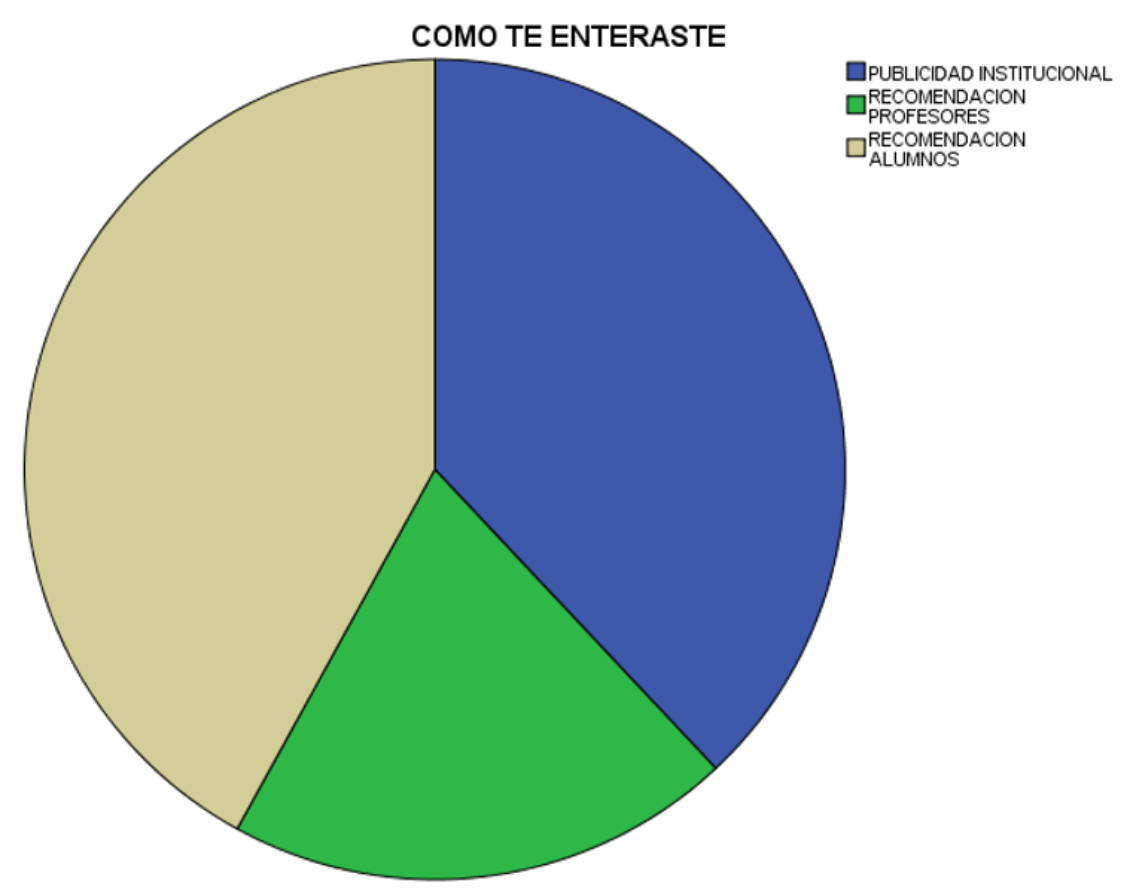


Funcionamiento. Los alumnos describen el funcionamiento de la plataforma con $24 \%$ equivalente a Malo, $72 \%$ con una buena percepción y $4 \%$ como excelente.

\section{FUNCIONAMIENTO}

\begin{tabular}{|ll|r|r|r|r|}
\hline & Frecuencia & Porcentaje & $\begin{array}{c}\text { Porcentaje } \\
\text { válido }\end{array}$ & $\begin{array}{c}\text { Porcentaje } \\
\text { acumulado }\end{array}$ \\
\hline Válidos & MALO & 12 & 24.0 & 24.0 & 24.0 \\
& BUENO & 36 & 72.0 & 72.0 & 96.0 \\
EXCELENTE & 2 & 4.0 & 4.0 & 100.0 \\
Total & 50 & 100.0 & 100.0 & \\
\hline
\end{tabular}

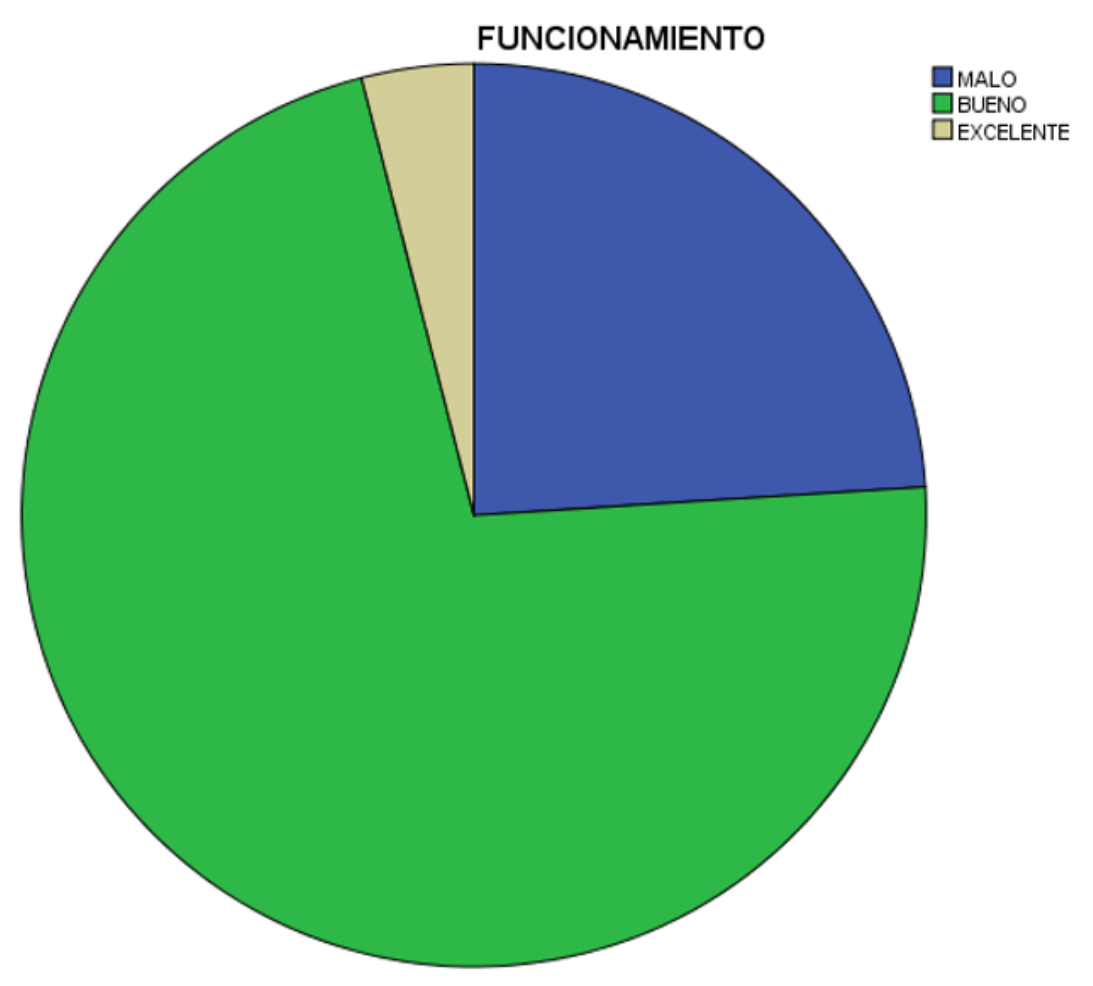


Relación con el Profesor. El 26\% considera que nunca existe una relación con el docente a cargo del curso, el 52\% dijo que rara vez existe relación y el $22 \%$ que Sí, a veces la hay.

\section{RELACION/PROFESOR}

\begin{tabular}{|ll|r|r|r|r|}
\hline & Frecuencia & Porcentaje & $\begin{array}{c}\text { Porcentaje } \\
\text { válido }\end{array}$ & $\begin{array}{c}\text { Porcentaje } \\
\text { acumulado }\end{array}$ \\
\hline Válidos & NUNCA & 13 & 26.0 & 26.0 & 26.0 \\
& RARA VEZ & 26 & 52.0 & 52.0 & 78.0 \\
& SI, AVECES & 11 & 22.0 & 22.0 & 100.0 \\
Total & 50 & 100.0 & 100.0 & \\
\hline
\end{tabular}

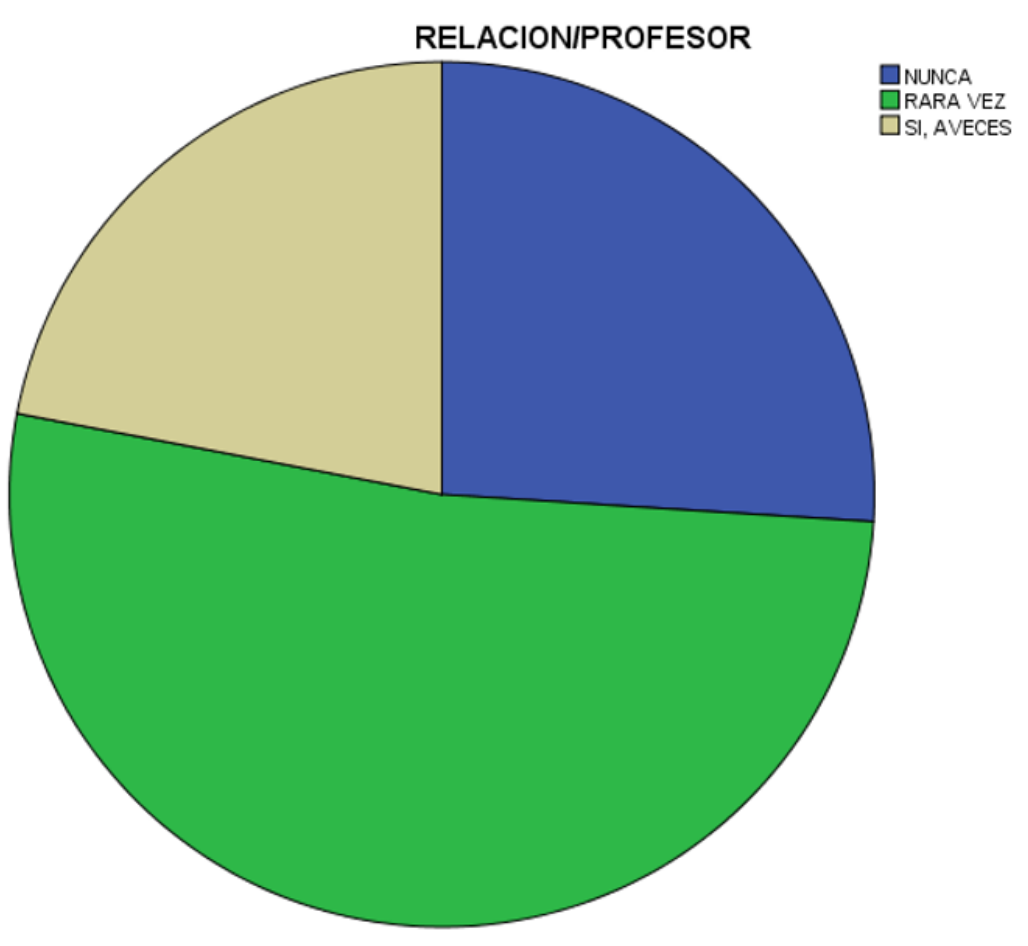


Principales Problemas. El 30\% de los alumnos considera que la comunicación es uno de los problemas que aqueja a la plataforma de educación a distancia mientras que el $34 \%$ dijo que es la interacción entre los principales actores del curso, el $30 \%$ se refirió a que es la adaptabilidad que ellos mismos pudieran tener para el uso de la plataforma y el $6 \%$ considera que no hay ningún problema.

PRINCIPALES PROBLEMAS

\begin{tabular}{|ll|r|r|r|r|}
\hline & Frecuencia & Porcentaje & $\begin{array}{c}\text { Porcentaje } \\
\text { válido }\end{array}$ & $\begin{array}{r}\text { Porcentaje } \\
\text { acumulado }\end{array}$ \\
\hline Válidos & COMUNICACION & 15 & 30.0 & 30.0 & 30.0 \\
& INTERACCION & 17 & 34.0 & 34.0 & 64.0 \\
ADAPTABILIDAD & 15 & 30.0 & 30.0 & 94.0 \\
NINGUNO & 3 & 6.0 & 6.0 & 100.0 \\
Total & 50 & 100.0 & 100.0 & \\
\hline
\end{tabular}

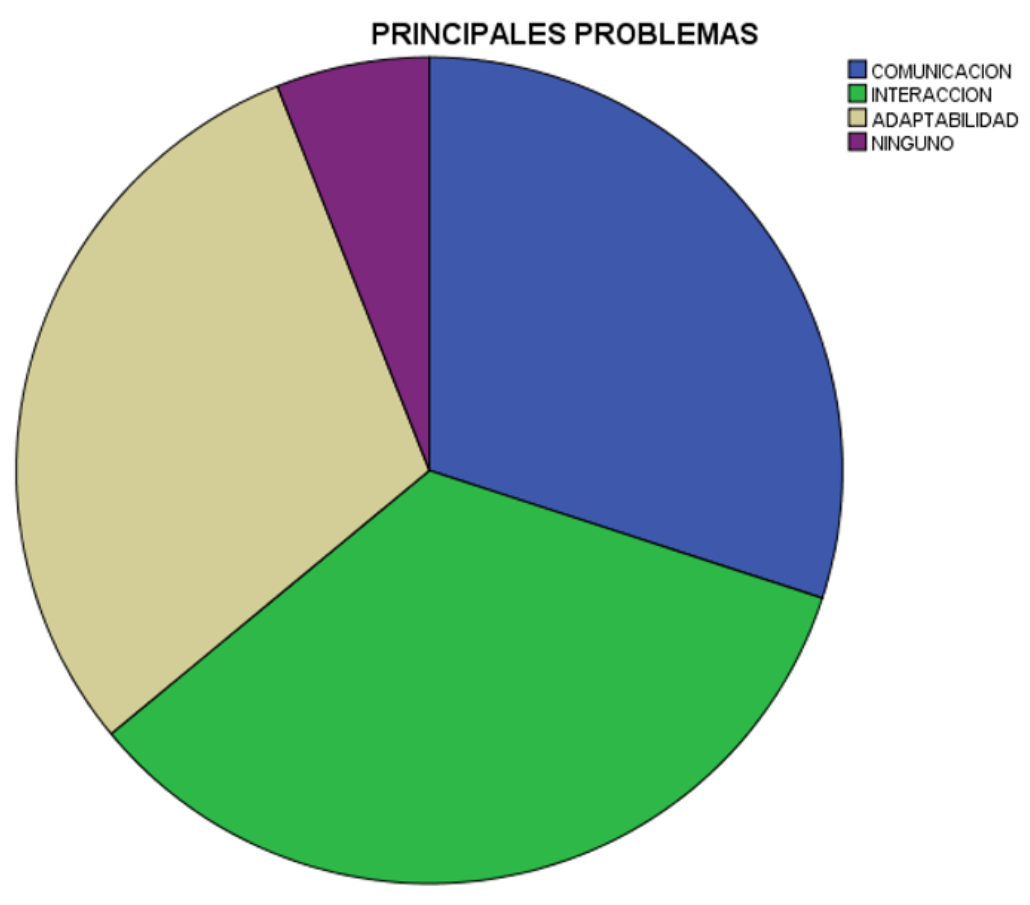


Implementación de Herramientas. En consideración si hace falta o no la implementación de herramientas modernas para mejorar la interacción y comunicación de la plataforma entre alumno-docente, el 92\% de los alumnos dijeron que sí es necesario mientras que el $8 \%$ dijo que no.

IMPLEMENTACION/HERRAMIENTAS

\begin{tabular}{|ll|r|r|r|r|}
\hline & Frecuencia & Porcentaje & $\begin{array}{c}\text { Porcentaje } \\
\text { válido }\end{array}$ & $\begin{array}{c}\text { Porcentaje } \\
\text { acumulado }\end{array}$ \\
\hline Válidos & SI & 46 & 92.0 & 92.0 & 92.0 \\
& NO & 4 & 8.0 & 8.0 & 100.0 \\
& Total & 50 & 100.0 & 100.0 & \\
\hline
\end{tabular}

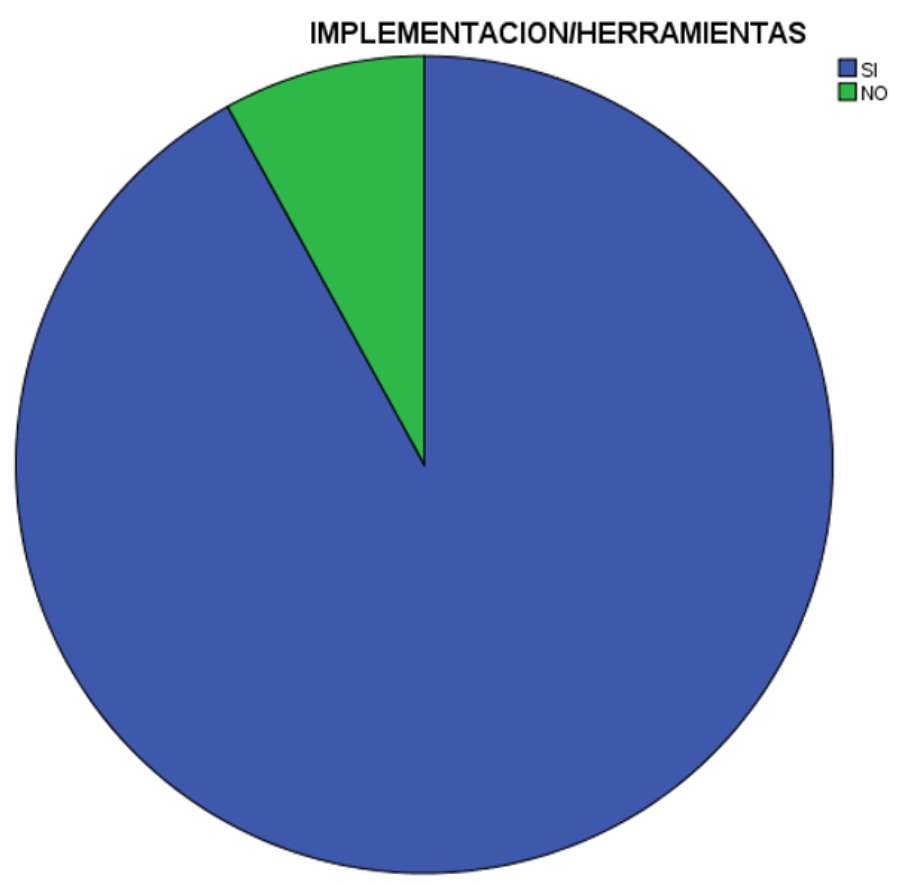


Interacción Alumno - Docente. Para el 88\% de los alumnos es necesario que exista una interacción entre el alumno y el docente del curso mientras tanto para el $12 \%$ considera que no es necesario.

INTERACCION ALUM/DOCE

\begin{tabular}{|rl|r|r|r|r|}
\hline & Frecuencia & Porcentaje & $\begin{array}{c}\text { Porcentaje } \\
\text { válido }\end{array}$ & $\begin{array}{r}\text { Porcentaje } \\
\text { acumulado }\end{array}$ \\
\hline Válidos & SI & 44 & 88.0 & 88.0 & 88.0 \\
& NO & 6 & 12.0 & 12.0 & 100.0 \\
& Total & 50 & 100.0 & 100.0 & \\
\hline
\end{tabular}

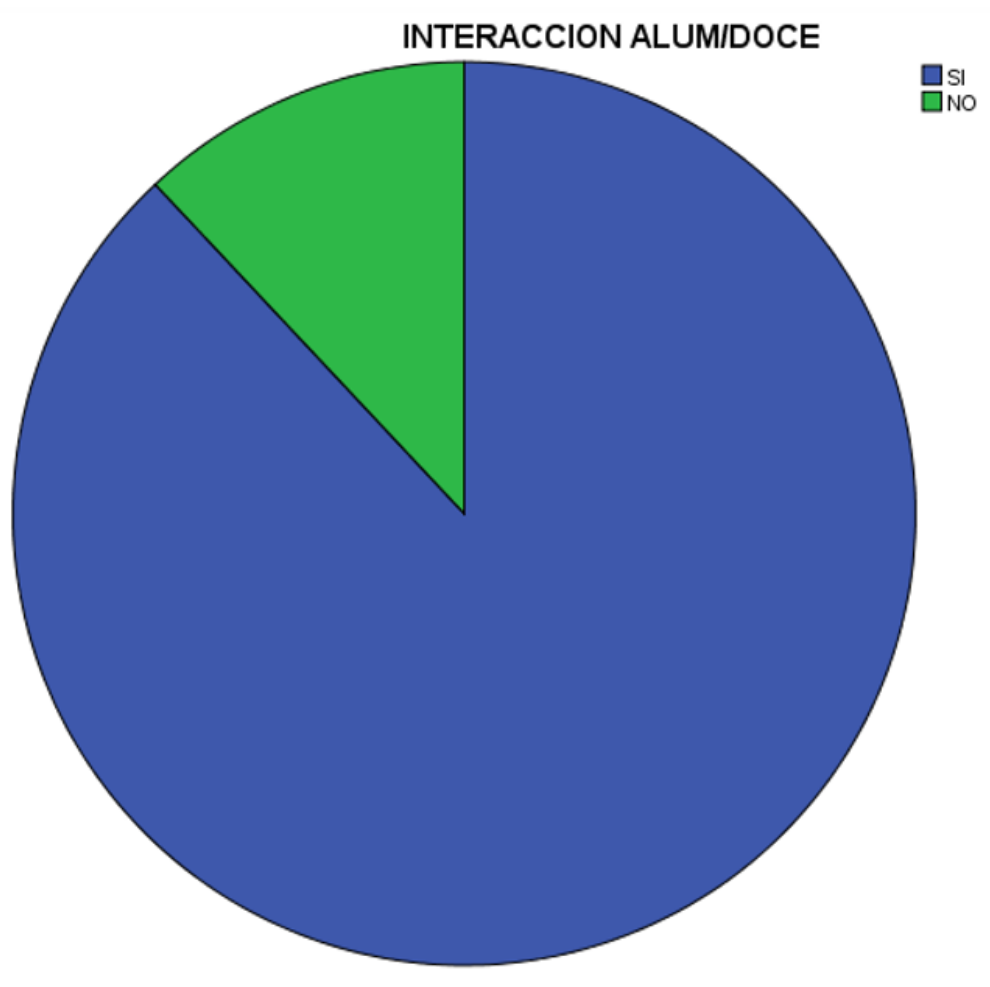


Herramientas Tecnológicas. De las herramientas tecnológicas que los alumnos consideran deberían implementarse para mejorar el proceso de la plataforma están; Facebook 32\%, WhatsApp 26\%, Skype 36\% y Twitter 4\% y en otro punto de vista fuera de las herramientas tecnológicas mencionadas solo el $2 \%$ dio otra respuesta fuera de las mencionadas.

HERRA.TECNOLOGICA

\begin{tabular}{|ll|r|r|r|r|}
\hline & Frecuencia & Porcentaje & $\begin{array}{c}\text { Porcentaje } \\
\text { válido }\end{array}$ & $\begin{array}{c}\text { Porcentaje } \\
\text { acumulado }\end{array}$ \\
\hline Válidos & FACEBOOK & 16 & 32.0 & 32.0 & 32.0 \\
& WHATSAPP & 13 & 26.0 & 26.0 & 58.0 \\
SKYPE & 18 & 36.0 & 36.0 & 94.0 \\
TWITTER & 2 & 4.0 & 4.0 & 98.0 \\
5 & 1 & 2.0 & 2.0 & 100.0 \\
Total & 50 & 100.0 & 100.0 & \\
\hline
\end{tabular}

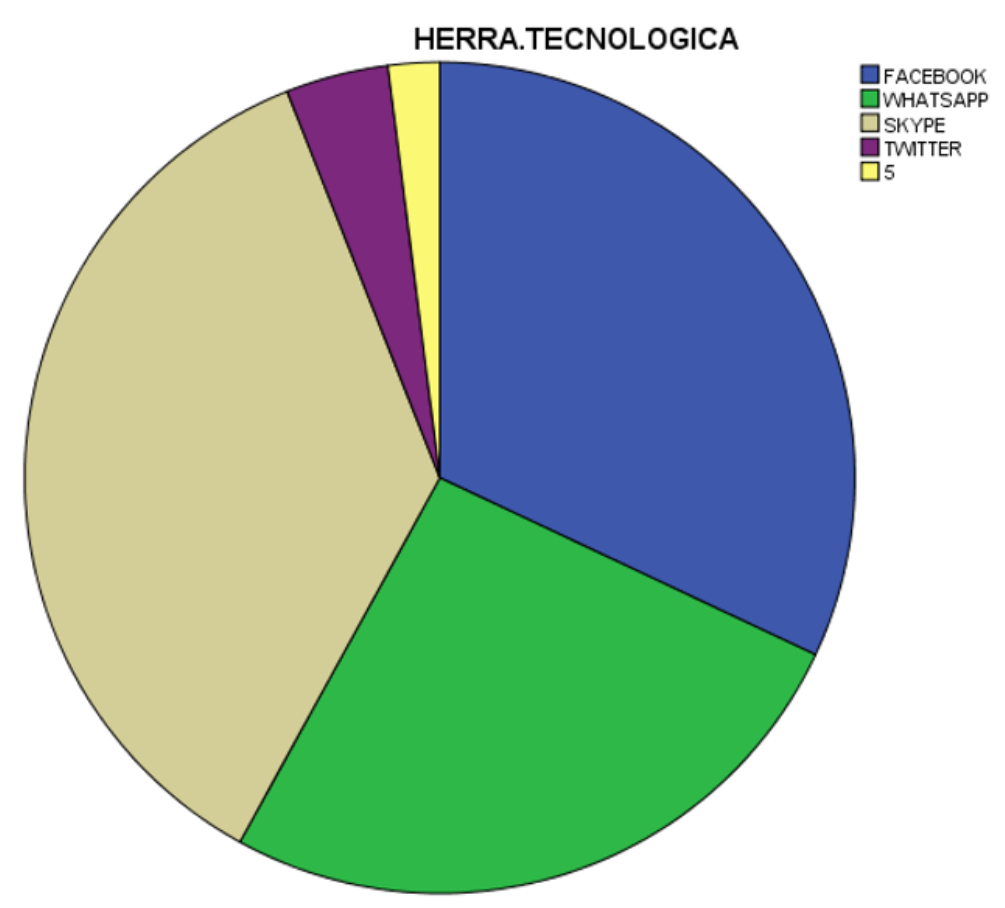


Reto Tecnológico. En cuestión de considerar la opción de educación a distancia como un reto tecnológico los alumnos dijeron; el $22 \%$ que si lo es porque no cuentan con internet en sus casas, el $40 \%$ que no y el $38 \%$ que algunas veces por la negativa que los profesores presentan en el curso.

\begin{tabular}{|c|c|c|c|c|c|}
\hline \multicolumn{6}{|c|}{ RETO TECNOLOGCO } \\
\hline & & Frecuencia & Porcentaje & $\begin{array}{l}\text { Porcentaje } \\
\text { válido }\end{array}$ & $\begin{array}{l}\text { Porcentaje } \\
\text { acumulado }\end{array}$ \\
\hline \multirow[t]{4}{*}{ Válidos } & $\begin{array}{l}\text { SI, SIN ACCESO A } \\
\text { INTERNET }\end{array}$ & 11 & 22.0 & 22.0 & 22.0 \\
\hline & NO, PARA NADA & 20 & 40.0 & 40.0 & 62.0 \\
\hline & $\begin{array}{l}\text { ALGUNAS VECES, } \\
\text { NEGATIVA DOCENTE }\end{array}$ & 19 & 38.0 & 38.0 & 100.0 \\
\hline & Total & 50 & 100.0 & 100.0 & \\
\hline
\end{tabular}

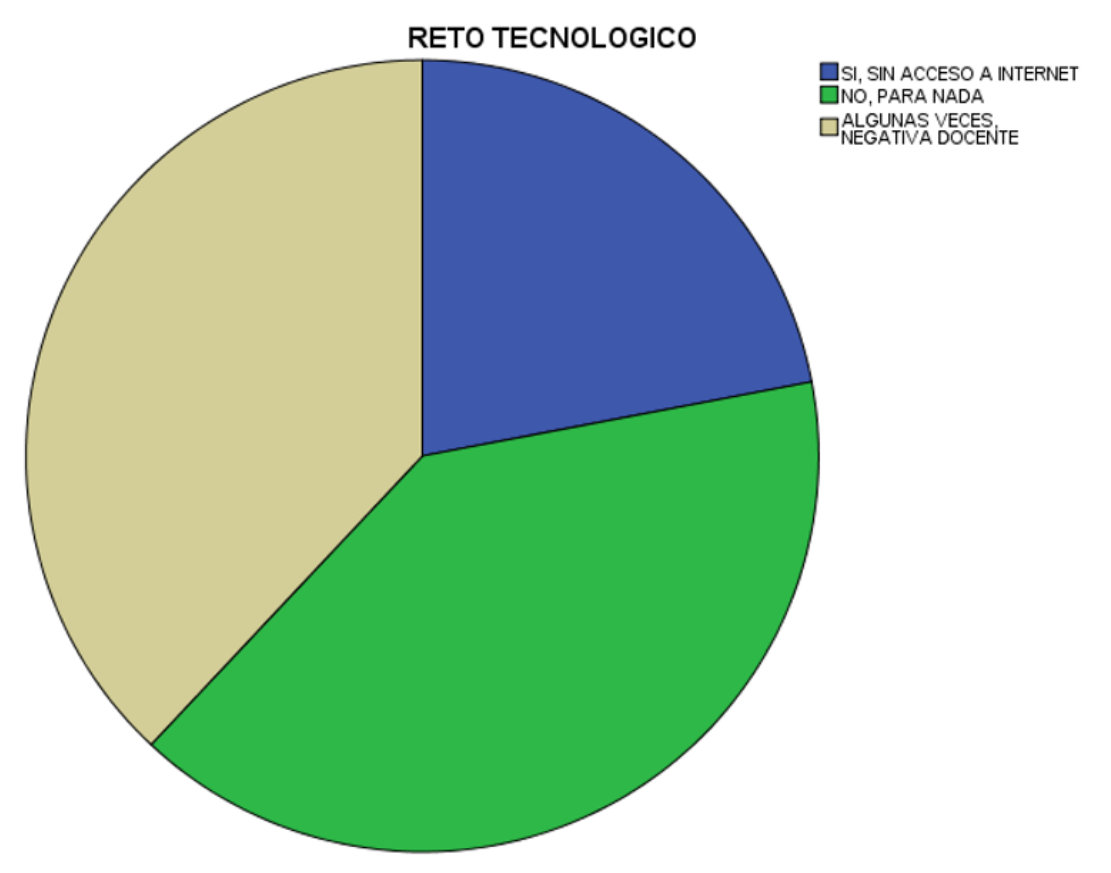




\section{CONCLUSIÓN}

En conclusión a este trabajo al aplicar la herramienta de cuestionario de donde se obtuvieron los resultados graficados con el SPSS, con la participación de 50 alumnos tomados como población que ha tenido acercamiento a los procesos de educación a distancia con la plataforma SEAD-UJAT central de la Universidad Juárez Autónoma de Tabasco. Tomando como polo de referencia la pregunta que se manejó:

¿Qué factores intervienen en la falta de interactividad y comunicación alumno-docente dentro de la plataforma de educación a distancia en la universidad Juárez Autónoma de Tabasco?

Con los resultados obtenidos por la estadística descriptiva; damos respuesta a la pregunta principal de la investigación donde el $38 \%$ de los datos indica que un factor determinante y el más alto es la negativa que los profesores presentan durante el desarrollo del curso, considerando lo que se manejó de principio en el planteamiento del problema y la justificación; en su mayoría los alumnos se quejan de la poca importancia que el docente le presta al curso; ya que por información ofi- cial e institucional en donde muchas veces los profesores figuran en organigramas estructurales de la institución se observa que estos profesores igual son personal administrativo; cubren cargos específicos en las diferentes divisiones académicas y secretarías de la universidad por ello es un tanto más difícil atender las actividades de sus cursos asignados, aclarando que no se está generalizando a todos ya que los resultados también indican que otro de los factores es la falta de internet en casa este factor se indica con el $22 \%$ lo cual es un hallazgo que no se tuvo contemplado nunca como un factor determinante, se puede decir que esto imposibilita al alumno a estar en contacto con el docente.

El cumplimiento del trabajo propuesto: Se determinaron dos factores de incidencia, se cumplió con el objetivo principal y se encontró que los principales problemas que existen en la plataforma son la interacción en un 34\% que se atribuye a la poca disponibilidad 0 interés que a veces se presenta por los docentes y por el factor de no contar con internet en casa, fungen como barreras de interacción y que de igual forma afectan a la comunicación

Se cumplió con el objetivo principal y se encontró que los principales problemas que existen en la plataforma son la interacción en un 34\% que se atribuye a la poca disponibilidad o interés que a veces se presenta por los docentes y por el factor de no contar con internet en casa

eficiente; la comunicación se colocó con $30 \%$ siendo el segundo problema detectado.

La solución o recomendación que se obtiene de esta investigación hacia la institución educativa, es el uso y/o mejor implementación de las actuales herramientas tecnológicas en donde la gran parte de los alumnos tiene acceso, considerado por los resultados, implementar el Skype como método de interacción directo con el alumno, así habría mejor feedbackalumno-docente.

También contempla las aplicaciones Facebook y WhatsApp como herramientas realmente prácticas y eficientes que derribarían barreras que están ahí pero que pueden ser minimizadas.

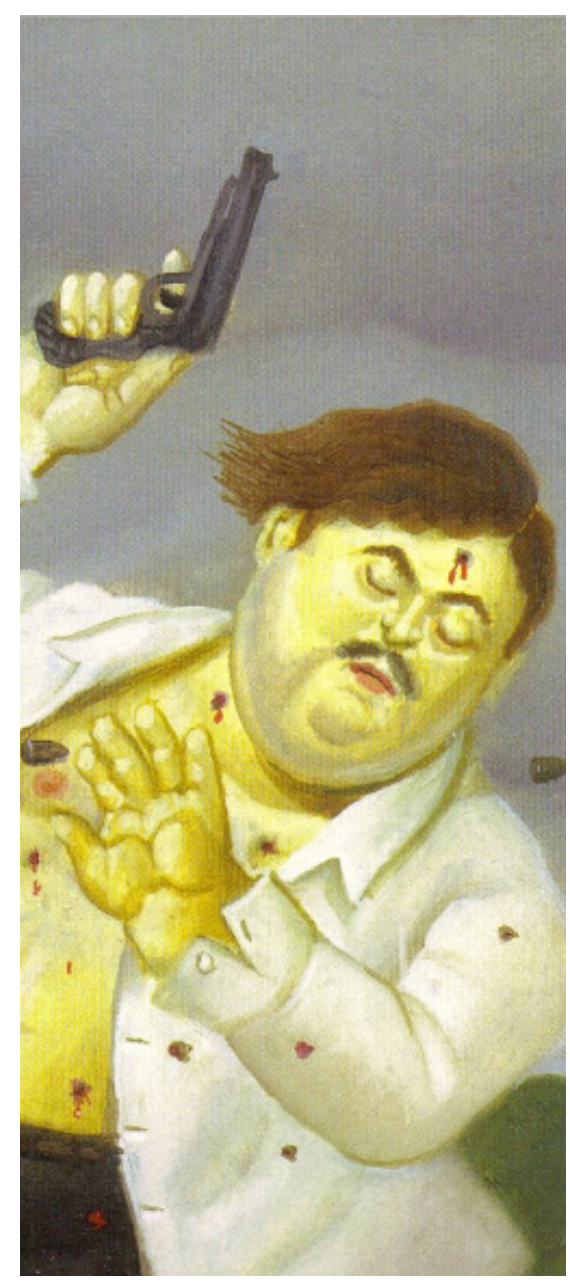

Preparatoria 8 UANL 


\section{REFERENCIAS}

Bates, T. (1995). Technology, open learning and distance education. Londres, Inglaterra.

Bosco, M. D. \& Barrón, H. S. (2008). La educación a distancia en México: Narrativa de una historia silenciosa. DF, México.

Corrales, M. I. (2008). Metodología de la formación abierta y a distancia, DF, México.

Delgado, K. (S.F). Las plataformas en la educación a distancia en México.

Del toro, B. P. (S.F.). La educación a distancia y las TICS como apoyo para la enseñanza y el aprendizaje en ciencias de la salud.

García, L. (2001). La educación a distancia De la teoría a la práctica. Barcelona, España.

García, L. (2011). Nueva entrevista: La interacción es elemento definitorio del hacer educativo.

Galeano, E. C. (S.F). Modelos de comunicación.

González, G. (2005). Origen y desarrollo de la educación a distancia en México. Jardines, FJ. (2009). Desarrollo histórico de la educación a distancia, San Nicolás De Los Garza, NL, México.

Kiss de Alejandro, D. M., (2006). Niveles de interacción en la comunicación en Internet. Ámbitos, 45-57.

Kramarae, C. (2001). Third Shift: Women Learning Online. Washington, Dc. UU.EE Martínez de Velasco, A. y Nosnik, A. (2002). Comunicación organizacional práctica manual gerencia. DF, México.

Maya, A. (1993). La educación a distancia y la función tutorial. San José, Costa Rica.

Mena, M. (2004). La Educación a Distancia en América latina Modelos, tecnologías y realidades. Buenos Aires, Argentina.

Moore, M. G. \& Kearsley, G. (2005). Distance Education: A Systems View of Online Learning, Belmont, CA, EE. UU.

Moreno, M. (2006). Una historia de la educación a distancia en México. Guadalajara, México.

Nabel, L. C. (2006). La educación a distancia en México: ¿quién y cómo la hace? Apertura, 6, 74-89.

Ongallo, C. (2007). MANUAL DE COMUNICACIÓN. Guía para gestionar el conocimiento, la información y las relaciones humanas en empresas y organizaciones. Madrid.

Passerini, K. \& Granger, M.J. (2000). A Developmental Model for distance learning using the Internet. Computers \& Education, Washington, Dc, EE. UU.

Quijada, V. \& Torres, A. (S.F). El proceso de comunicación las barreras de la comunicación.

Rambo,A. R. (2009). Plataformas de educación a distancia.

Rizo, M. (2006). George Simmel. Sociabilidad e interacción, aportes a la ciencia de la comunicación. México.

Ronchi, R. (2005). Plataformas para la educación a distancia.

Santos, C. M. (2010). En la UJAT. Historia de la educación a distancia. los primeros pasos. 


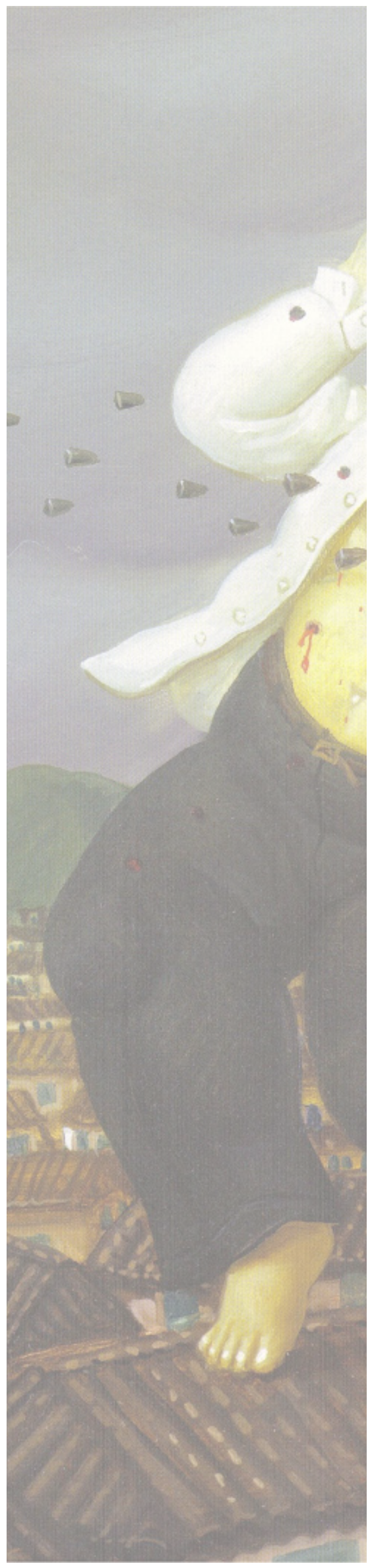

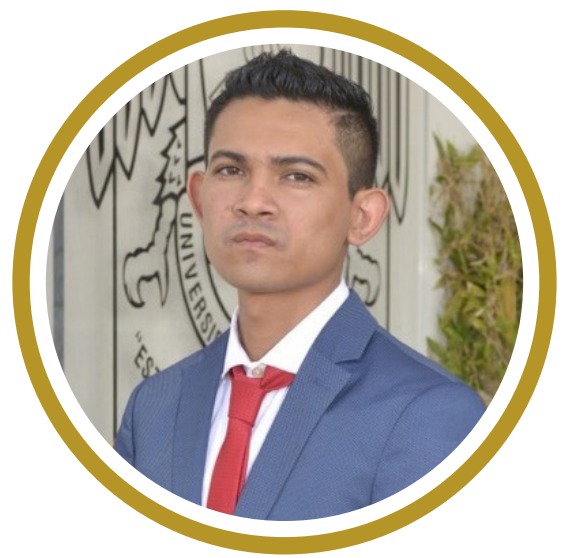

\section{Guadalupe Emmanuel Jiménez Margalli}

Profesor de Educación Básica, especialmente del Sistema Nacional de Telesecundaria. Egresado de la Licenciatura en Ciencias de la Educación de la División Académica de Educación y Artes de la Universidad Juárez Autónoma de Tabasco. Ha logrado durante los años de experiencias, combinar la docencia con la investigación en aspectos relacionados con las percepciones de los estudiantes de educación básica y universitaria. Ha participado como colaborador en diversos proyectos de intervención social y de investigación.

Correo Electrónico:

jimenezmargalli@gmail.com

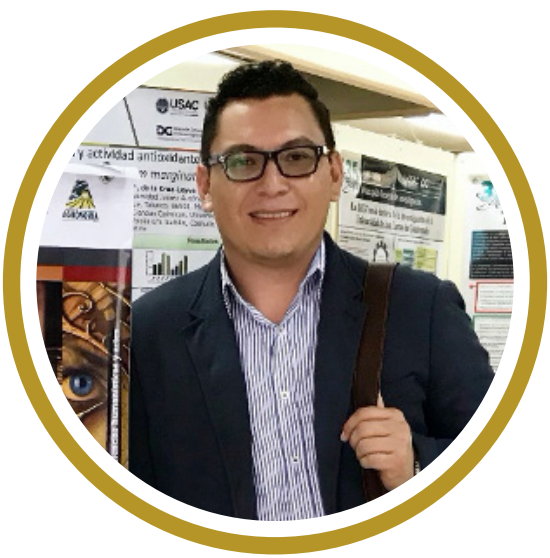

\section{Rigoberto García Cupil}

Licenciado en Ciencias de la Educación (UJAT); maestro en Ciencias de la Educación (IEU Puebla), con especialidad en: Experto Universitario en Nuevos Ambientes de Aprendizaje por el Consorcio Virtual Educa Argentina. Miembro de Comités Interinstitucionales para la Evaluación de la Educación Superior, A.C. CIEES. Miembro Estatal del Padrón de Investigadores (Tabasco). Es Evaluador Nacional al Desempeño Docente por la Coordinación Nacional del Servicio Profesional Docente y el Instituto Latinoamericano de la Comunicación Educativa. Profesor Investigador de Tiempo Completo de la División Académica de Educación y Artes de la Universidad Juárez Autónoma de Tabasco.

\section{Correo Electrónico:}

gacuri7@hotmail.com

Fecha de Recepción: 15/03/20

Fecha de Aprobación: 15/08/20 